\title{
The influence of the geometrical parameters on the mechanical properties of honeycomb structure
}

\author{
Malgorzata JOHN*, Antoni JOHN**, Wojciech SKARKA*** \\ *Silesian University of Technology, Faculty of Mechanical Engineering, Institute of Fundamentals of Machinery Design, \\ Konarskiego 18A, 44-100 Gliwice, Poland, E-mail: malgorzata.john@polsl.pl \\ **Silesian University of Technology, Faculty of Mechanical Engineering, Institute of Computational Mechanics and \\ Engineering, Konarskiego 18A, 44-100 Gliwice, Poland, E-mail: antoni.john@polsl.pl \\ ***Silesian University of Technology, Faculty of Mechanical Engineering, Institute of Fundamentals of Machinery \\ Design, Konarskiego 18A, 44-100 Gliwice, Poland, E-mail: wojciech.skarka@polsl.pl
}

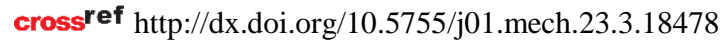

\section{Introduction}

Additive Technologies extend its scope, so far been used primarily for the presentation of the newly developed elements and geometric verification increasing use of elements produced in these technologies as a target produced small series structure poses new challenges as to their form and internal design features [1, 2]. Significant become their strength characteristics and durability. At the same time it should be noted that the current production technologies is not until such great opportunities for development of component form as commonly used and developed technologies additive. Existing systems for shaping the internal structure based primarily on land use geometric shape of the internal space realizing only a supportive function for external shapes based on the criterion of fill material, allowing you to reduce the amount of material used. For structural applications, it is necessary to adopt other criteria shaping the structure eg. the criterion of strength. This places entirely new demands on the approach to the development of the internal form of the element made in additive technology.

Homogenic structure based on honeycomb pattern which is used while shaping the inside of the elements made in additive technologies, can be replaced by heterogenic structure which ultimately will assure optimal strength and mass properties. The research has been carried in a few stages.

At the first stage it has been decided to test the structures which are similar to those which we can see in bones as a pattern of final structure. These types of structures have been tested in this stage as well as the choice of optimal calculation parameters which are used in these cases has been made.

Comparative studies of analytical and experimental research results have been carried at the next stage. The subject of the research was a typical orthogonal sample used in bending tests. Comparative studies covered samples prepared from cortical bone tissue.

The third stage covered elaboration and testing of numerical samples of the same shape but with the use of filling in a form of a honeycomb of different sizes allowing to create heterogeneous structures similar to the bones structure.

At the next stage the structure of samples has been elaborated which was of completely new inner form shaped as superposition of previously developed structures together with newly elaborated heterogeneous structure of changeable size of honeycomb cells. The orthogonal sample created in this way for bending tests has been subjected to numerical tests. The test results have been compared with initial structures of orthogonal samples based on the filling of typical, non-modified honeycomb.

The work focused mainly on the presentation of tasks and results from the third and fourth steps.

\section{Experimental and numerical research of bone}

Femur in its central part has a cross tube, which gives it, with such a small cross section, high strength properties. It is built from cortical bone. The upper part is the femoral head, which is composed of trabecular bone, like the neck [3]. Bones tissue, as composite materials, including various types of inclusions, which, from a technical point of view, can be classified as dispersed inclusions, fibers, layers or even three-dimensional trusses. They provide resistance to shear stress and normal, and particularly to prevent the propagation of cracks.

Mostly study the properties of these structures is carried out on small samples prepared from whole bones or ligaments, tendons, etc. Tests on samples held in the specific load conditions, when they are known directions of the stresses and strains. In general, the studies of tissue material properties are referred to during the stretching, bending and twisting [4]. It should be noted the place of download, whether it was a fresh tissue, lotions or dried, the description of the donor (age, weight, sex, etc.) as well as the conditions for implementation of measurement $[3,5,6]$.

The studies focused particularly on the cortical and trabecular bone. It was well known that cortical bone carries most of the load. It can be particularly observe in pelvic bone where the outer layer is composed of cortical bone and inner layer of trabecular bone, respectively [3]. Exceptions are the epiphysis of long bones which are built of trabecular bone and carry loads in joints. This structure seemed to us to be very interesting as the support structure. Therefore, the experimental studies carried out on samples prepared from human femur. The aim of this study was to determine the mechanical properties of prepared samples. On the basis of attempts to three-point bending test assumed Young modulus value to $15 \mathrm{GPa}$. The influence of tetrahedral elements (Fig. 1) with square or linear shape function and the solid 8node elements with a square or a linear shape function on the accuracy of stress and displacement values was tested. 
The size of the elements (mesh density) was also changed.

Based on the analysis of the results of numerical simulation it was selected as the optimal model comprising the 8-node solid elements with a linear shape function and dimension of $0.4 \mathrm{~mm}[7,8,9,10]$. In the process of developing the model it is noted that the density and distribution of the type of used components influence on received distributions of stresses and displacements.

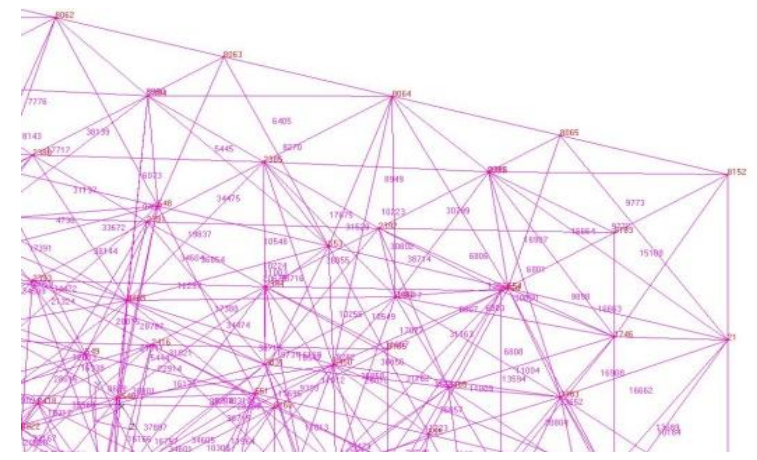

Fig. 1 Finite element grid model of the sample

However, increasing the degrees of freedom of the elements through the use of square shape function (elements Tet10 and Hex20 type) did not significantly affect the improvement of the obtained results and at the same time significantly increased computation time. In the next step we also tested the effect of change in the size of the elements (mesh density) on obtained results.

Bone, in its internal structure, is heterogeneous with respect to placement of the cells and their type. In the case of the numerical model it focuses on the trabecular (in a lesser sense cortical) part of the human femur. Therefore, proposing a bone tissue structure (Fig. 2, [11]) as the internal structure of the exoskeleton support elements omitted in the construction of the numerical model of trabecular structure. The arrangement of bone cells within the structure depends on the loads that are transferred in a given place of bone. In this approach we adopted homogenous isotropic model of bone material. During the simulations, advanced in the process of building a numerical model, one can use the data obtained from CT studies and MIMIC system to take into account heterogeneity of bone tissue. Led by us study do not need to have as accurate results in this regard [10].

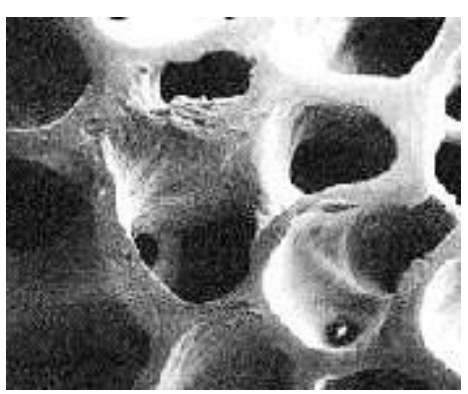

Fig. 2 Bone tissue architecture [11]

\section{Honeycomb structure}

Following the example of biological analogies we also proposes a structure based on the structure of the honeycomb. Industry is constantly looking for new materials and new structures in order to reduce weight, increase strength and get better value of other mechanical parameters. Sandwich structure consisting of a core and cladding has been used in various industries such as aerospace, shipbuilding, automotive industry. The core layer in most cases is thicker than the outer layer [12-15]. Such a structure greatly vary its properties of conventional construction, inter alia, due to the anisotropy of stiffness. Both materials are in themselves strong and rigid, but the composite formed from them has much rigidity and strength. It has several important features that are important in designing and developing in these industries. This structure is characterized by a relatively low weight in relation to mechanical properties [16]. Modifying the core and cladding can affect these properties. An interesting feature is the ability to absorb and absorption characteristics in a wide range of frequencies from infrasound, vibration or mechanical, to the acoustic vibration frequencies or tones [17]. The structure also showed resistance to corrosion in the marine environment and heat resistance. In the aerospace industry and shipbuilding proved significant weight construction. The automotive industry has focused mainly on the properties described absorbent structure. It turns out to be useful for building security systems. It has been proposed to examine, whether that structure is suitable for the support elements. There were prepared several numerical models of homogeneous structure (Fig. 3). Edited parameters based on hexagonal cells having a wall thickness of, inter alia, the dimensions of the cells.

In the next stage, it was decided to make a change and go to the heterogeneous structure. Inspired by the existing solutions we adapted them to the relevant issues. In the literature we can find many papers concern topology optimization problem for $2 \mathrm{D}$ and $3 \mathrm{D}$ structures like beam, girder, cantilever or other massive support structures [1824]. Some of them also based on the similarity of biomechanical structures [25, 26, 27]. Although the initial shape (volume) is full and continuous, however, final design is very similar to the truss, according to the considered issues of flat or spatial.

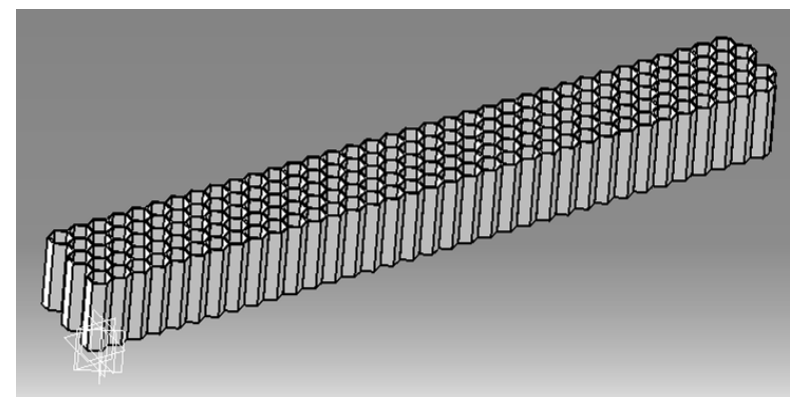

Fig. 3 An example of a numerical model of homogeneous structure

The results obtained in the topology optimization allow us to propose a structure which is a spatial truss in which the elements have different cross sections, different lengths and different arrangement.

Based on the literature review the changes to the cells overlap with the contour of the truss were proposed. In the place where the space should be filled with cells, it has a thicker wall. Due to the limitations imposed by the technology additive model can consist of a relatively large empty space. It is therefore proposed to fill in these cells hexagonal. They have for eg. thinner wall. 
Here proposed that the parameters which are prone to change they are wall thickness and cell size. In the case of wall thickness variations in the contour of the grid cell will have a thicker wall than the other. When the cell size will be changed in place of stroke it occurs density smaller cells. In the areas of "empty" cells it will be less, as will be higher. In the first stage it was decided to examine the effect of wall thickness on the obtained results. The dimensions of the model, the approximate dimensions of the tested bone samples were $4 \times 4 \times 40 \mathrm{~mm}$. We adopted this assumption in order to facilitate comparison of the obtained results. Away from the base to the opposite side of the cube was $1 \mathrm{~mm}$. This is an external dimension of a cell. At this stage, we adapted it to the outer dimensions of the model. Changes in internal dimensions - wall thickness - result in a decrease or increase the free space inside the cell. All it correlated to the value of $1 \mathrm{~mm}$.

The wall thickness was $0.4 \mathrm{~mm}$ maximum and a minimum of $0.05 \mathrm{~mm}$. It decided to make changes in different ways. The basic wall thickness is assumed to be 0.25 . The initial model was uniform and the wall thickness of each cell is the same. Initially, the increased wall thickness situated on the outline of the grid and at the same time reduces the thickness of the cell walls outside contour. In a next step it was decided that the difference between the thickness and a second cell is not too high. For example, when the contour of the cell wall in the grid has a wall thickness of $0.25 \mathrm{~mm}$, a cell wall beyond the periphery is $0.2 \mathrm{~mm}$ (Figs. 4-7).

In a further step it is proposed that underwent a change in cell dimensions and the wall thickness in each case was similar. The maximum distance between opposite walls was $2 \mathrm{~mm}$, and $0.5 \mathrm{~mm}$ minimum. The wall thickness has been changing, but always all cells have the same.

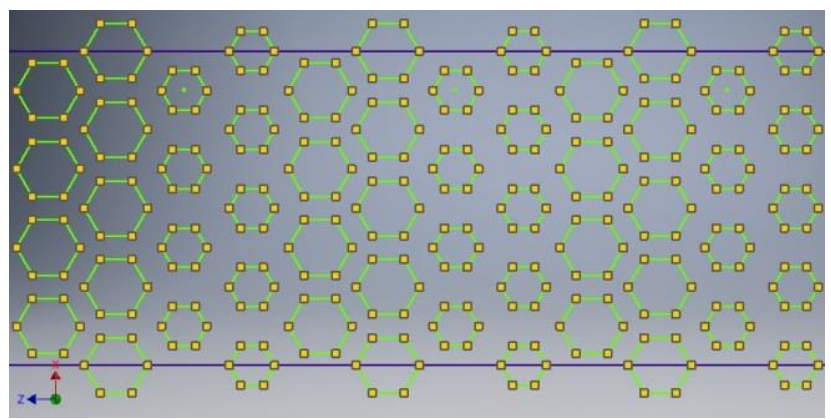

Fig.4 An example of the geometry of sample

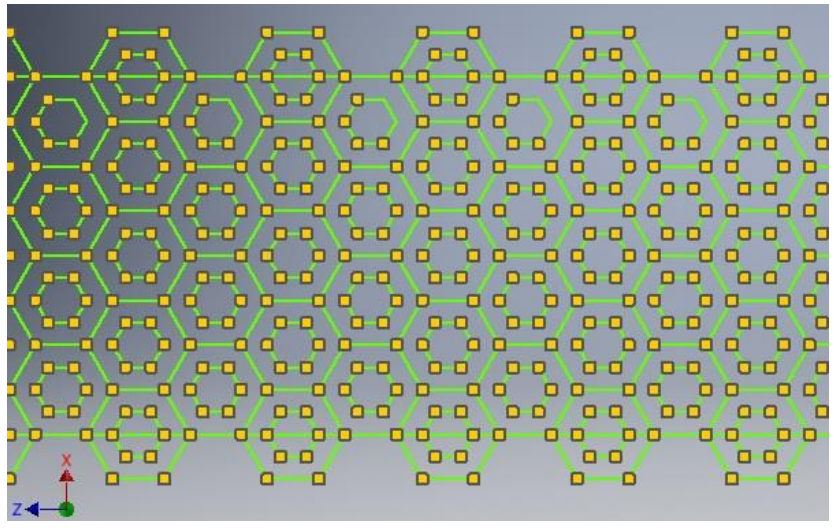

Fig. 5 Sample of the geometry of the specified wall thickness

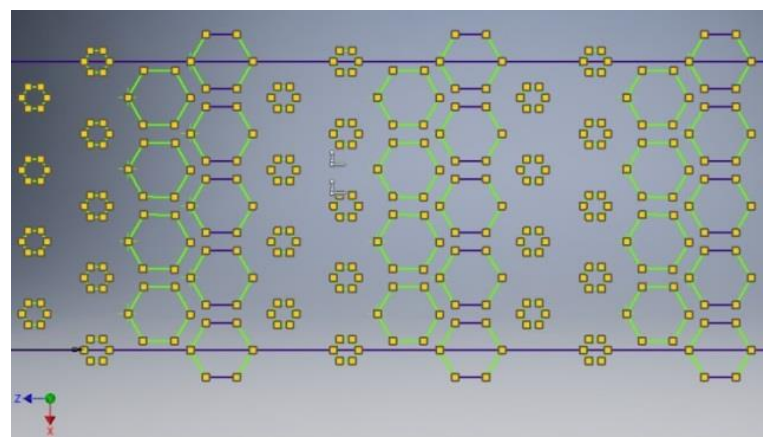

Fig. 6 An example of the geometry of the extreme dimensions of the voids in a sample

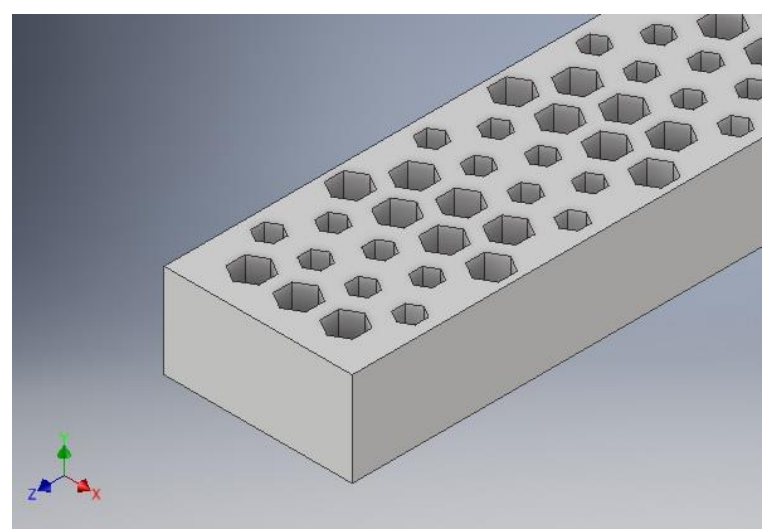

Fig. 7 Geometrical model of an one layer sample

\section{Numerical results}

When we talk about the "obtained results" we have in our mind the value of stresses and displacements in the model obtained during the simulation a three-point bending test. All numerically tested samples have the same dimensions as a previous tested samples prepared from cortical bone tissue. The sample with a length of $40 \mathrm{~mm}$, a height of $4 \mathrm{~mm}$ and $4 \mathrm{~mm}$ wide was modelled for two layers structure and sample with a height of $2 \mathrm{~mm}$ for one layer structure. Boundary condition (support and load) assumed as typical during tree-point bending test (Fig. 8). Acting force equals $5 \mathrm{~N}$.

Selectet examples of one layer and two layers FEM models show Figs. 8 and 9. In two layers models different pattern was used in construction of bottom and upper layer of structure. Fig. 10 shows bottom and upper view of structure in the same place, respectively.

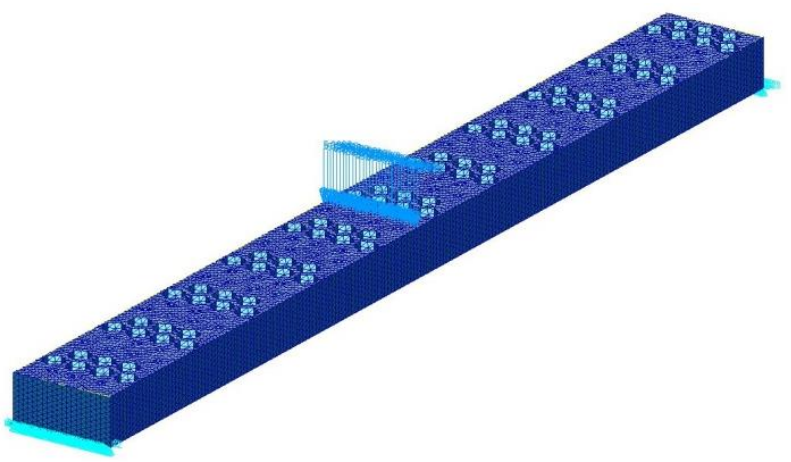

Fig. 8 One layer model with boundary conditions

Another exemplary of two layers model shows Fig. 11. Changes in the structure of the layers resulted in a 
change of simulation results. Enlarged view of bottom and upper surface of two layers structure presented in Fig. 11 shows Fig. 12. It is presented in the same place of sample.

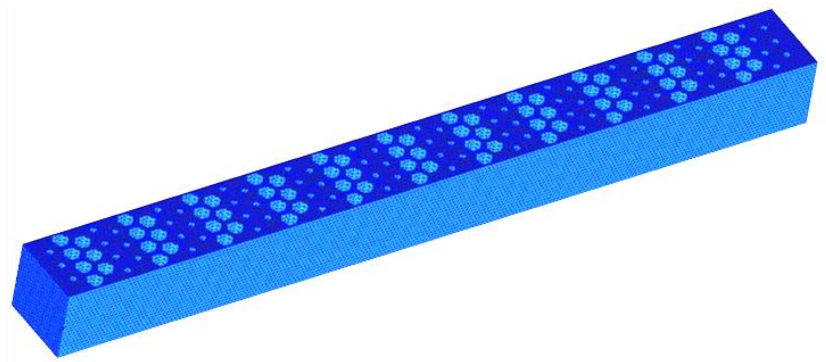

Fig. 9 Two layers FEM model
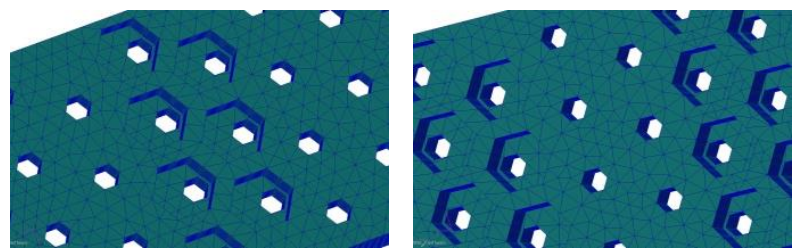

Fig. 10 Bottom (left) and upper (right) view of two layers structures

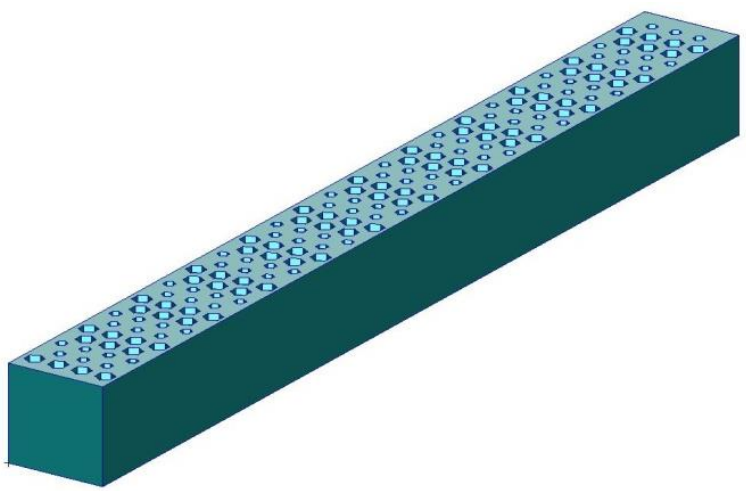

Fig. 11 Another exemplary of two layers FEM model
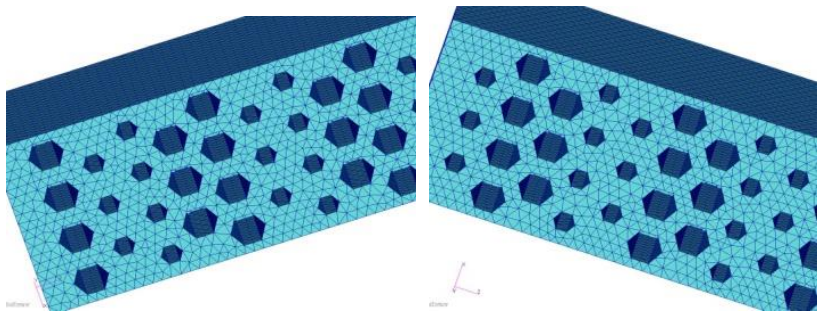

Fig. 12 Enlarged view of bottom and upper surface (in the same place) of two layers structure from Fig. 11

However, the displacement distribution for both, one layer and two layers model is typical as in bending (Figs. 13 and 14) nevertheless the distribution of von Mises reduced stresses (Figs. 15 and 16) and bending (normal) stresses (Figs. 17 and 18) are disrupted in sections where there are voids. One can observed that the larger the size of the void influence on the greater stress concentration.

Changes introducing in the sample structure effect on the decreasing of maximum value of displacement and stresses in two layers model and also in one layer model. In one layer model it can be observed that displacement equals $0.115 \mathrm{~mm}$ for initial configuration of the voids has decreased to $0.098 \mathrm{~mm}$ for the next configuration of the voids. The same trends were seen for two layers models. In that case displacement equals $0.011 \mathrm{~mm}$ for initial configuration of the voids has decreased to $0.0091 \mathrm{~mm}$ for the next configuration.

When the reduced von Mises stresses are taken into account it can be noticed decreasing initial maximum value (for initial configuration) from $166 \mathrm{MPa}$ to $109 \mathrm{MPa}$ for next configuration in one layer model. These same relationships exist for two layers models. Here, stresses has decreased from $21 \mathrm{MPa}$ to $16,7 \mathrm{MPa}$.

Bending stresses also changed and decreasing when the voids configuration is shaped in the right way.
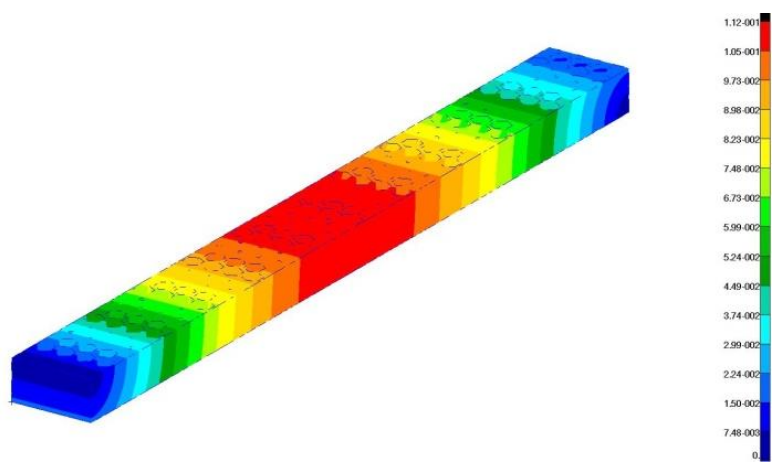

Fig. 13 Magnitude displacement in one layer model, in mm
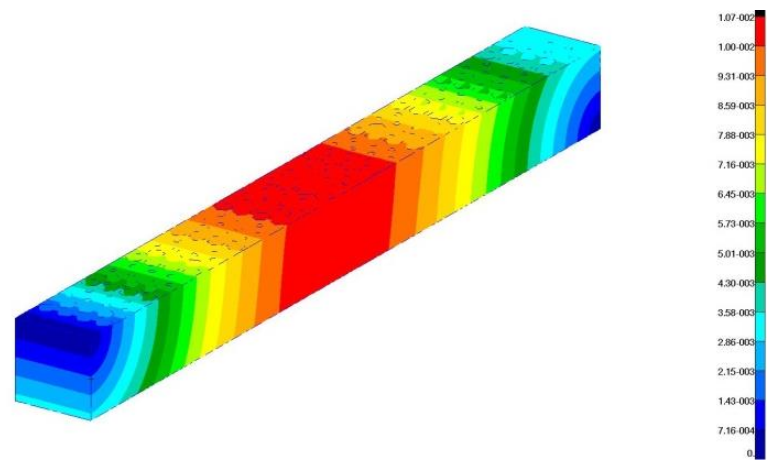

Fig. 14 Magnitude displacement in two layers model, in mm
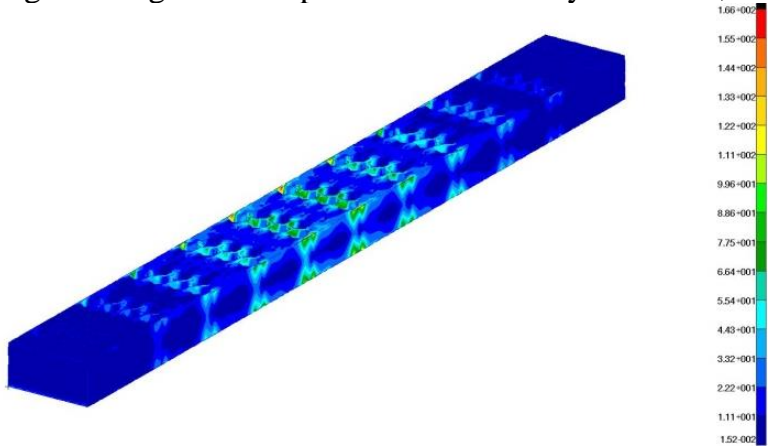

Fig. 15 Reduced stress distribution (von Mises) in one layer model, in $\mathrm{MPa}$
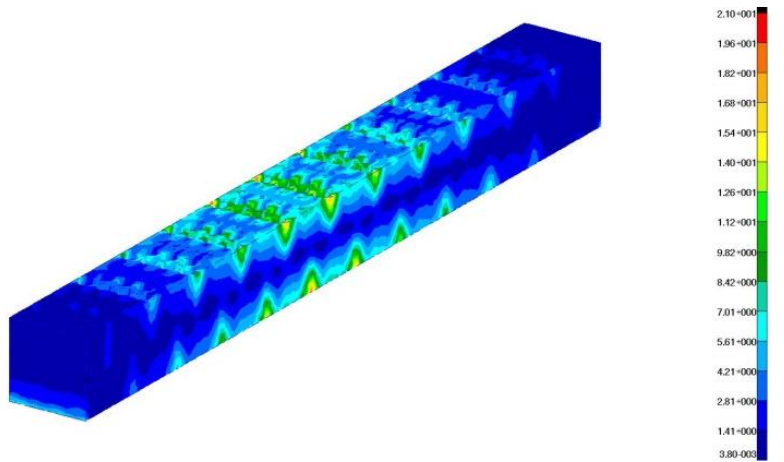

Fig. 16 Reduced stress distribution (von Mises) in two layers model, in $\mathrm{MPa}$ 
We can also observed significant reduction the value of displacement and stresses when we move from a single layer structure to the two. It coming from, not only increasing the cross-section of the beam but mainly, from the changing in internal structure of a sample.
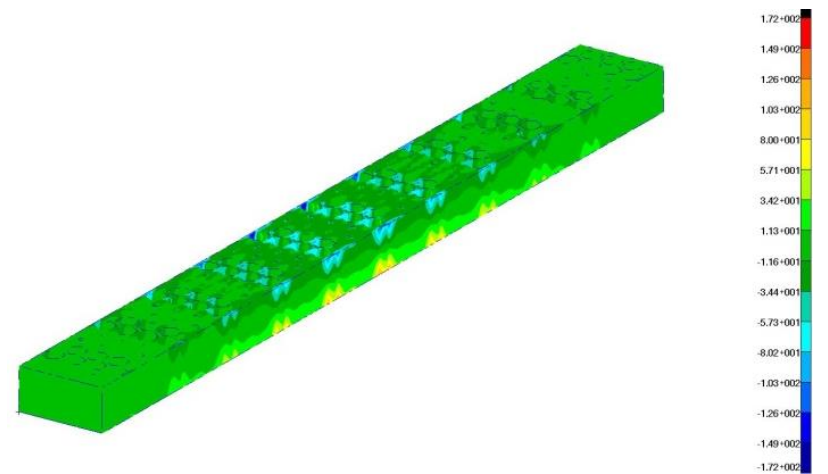

Fig. 17 Normal stress distribution in one layer model, in $\mathrm{MPa}$

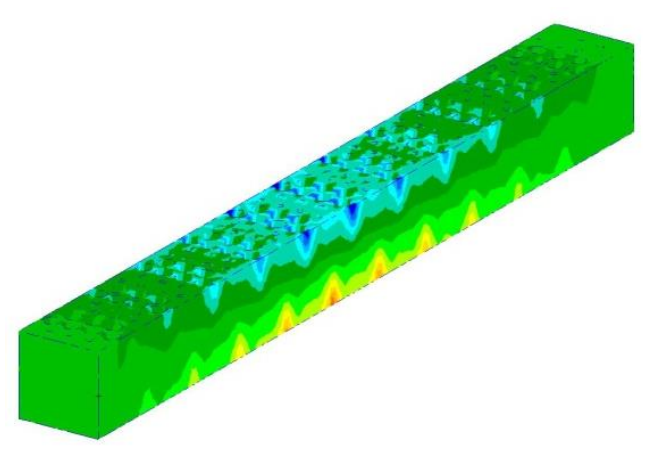

Fig. 18 Normal stress distribution in one layer model, in $\mathrm{MPa}$

Along with the reduction of empty space an improvement of the results. The introduction of too much free space resulted in a significant deterioration of the results. In some cases, they proved to be critical. Each model inhomogeneous was not better than the homogeneous model. In some cases, the obtained results were worse than the base case model. A similar phenomenon was observed when comparing the results between the models produced by changing the thickness of the walls, and where changes underwent cell dimensions base. It is impossible to say with certainty that some changes have a better impact on the obtained results, and other worse.

In further studies we propose to performed sensitivity analysis to indicate which factors (dimensions) are the most important.

\section{Conclusions}

It was observed that with decreasing free space in the model, and hence mass, the strength increases. At the same time stiffness of the sample increases too. Sometimes this phenomenon is good, but not in every case. The advantage of honeycomb structures is a high strength relative to a relatively low weight. When the cell walls are too thick or structure consist of densely cells it begin to lose the most important advantages of this construction. Despite receiving better strength results, they do not have to be the preferred models.

It can be seen that a very interesting solution is to materials, structures, which in their structure have free spaces contain air, other gas or liquid. They observed in these relatively good mechanical properties to the proportionally low weight. Such solutions can be found in nature. In the case of the honeycomb structure, it is homogeneous. When dealing with human bone, its structure is heterogeneous. The internal structure of the bone is adapted to carry the loads that occur in normal functioning of a human. Bone tissues, both trabecular and cortical tissues, are very good examples of the structures of heterogeneous, highly transferring asked load.

\section{References}

1. Jałowiecki, A.; Skarka, W. 2016. Generative Modeling in Ultra-Efficient Vehicle Design. Ed. by: Borsato, M; Wognum, N; Peruzzini, M; et al. 23rd ISPE Inc. International Conference on Transdisciplinary Engineering, Curitiba, BRAZIL, OCT 03-07, 2016 in Transdisciplinary Engineering: Crossing Boundaries, Book Series: Advances in Transdisciplinary Engineering, vol. 4, 9991008.

2. Skarka, W. 2015. Reducing the Energy Consumption of Electric Vehicles. Ed. by: Curran, R; Wognum, N; Borsato, M; et al., 22nd ISPE-Inc International Conference on Concurrent Engineering Location, Delft, Jul 20-23, 2015, Transdisciplinary Lifecycle Analysis of Systems, Book Series: Advances in Transdisciplinary Engineering, vol. 2, 500-509.

3. Będziński, R. 1997 Biomechanics Engineering. Selected problems, Oficyna Wydawnicza Pol. Wrocławska, Wrocław (in Polish).

4. Jakubowicz, A.; Orłoś, Z. 1978. Strength of materials, Wydawnictwa Naukowo-Techniczne, Warszawa 1978 (in Polish).

5. Kokot, G. 2013 Evaluation of bone tissues mechanical properties using digital image correlation, nanoindentation and numerical simulations, Wydawnictwo Politechniki Śląskiej, Gliwice (in Polish).

6. Keaveny, T.; Morgan, E.; Yeh, O. 2004 Bone Mechanics. w: Kutz, M. (Ed.): Standard handbook of biomedical engineering and design. McGraw-Hill.

7. John M.; John A. 2015. The influence of the model parameters of "honeycomb" structure on mechanical properties. Proc. of the 20th Int. Conf. Mechanika 2015, Kaunas: 116-119.

8. John M.; John A. 2016. Modeling and numerical analysis of honeycomb structures for application in sandwich structures. Proc. of the 21th Int. Conf. Mechanika 2016, Kaunas: 92-95.

9. John A.; John M. 2016. Foam metal and honeycomb structures in numerical simulation. ANNALS of Faculty Engineering Hunedoara - International Journal of Engineering, T. XIV, No. 4: 27-32.

10. John, M.; Skarka, W. 2014 Application to biological analogy development of the form of structural bearing components exoskeleton, Aktual. Probl. Biomech., 6368 (in Polish).

11. Godek, P. Functional architecture of skeleton - the possibility of Chiropractic., [online] [accessed 27 Febr. 2017]. Available from Internet: http://www.chiropraktycy.pl/p3.html (in Polish).

12. Abbadi, A.; Koutsawa, Y.; Carmasol, A.; Belouettar, S.; Azari, Z. 2009. Experimental and numerical characterization of honeycomb sandwich composite panels. 
Simulation Modelling Practice and Theory 17: 15331547.

http://dx.doi.org/10.1016/j.simpat.2009.05.008.

13. Fengnian J.; Hailong C.; Long Z.; at al. 2013. Failure mechanisms of sandwich composites with orthotropic integrated woven corrugated cores. Experiments, Composite Structures 98: 53-58.

http://dx.doi.org/10.1016/j.compstruct.2012.09.056.

14. Sadowski T.; Bęc J. 2011. Effective properties for sandwich plates with aluminium foil honeycomb core and polymer foam filling - Static and dynamic response. Comp. Materials Science 50: 1269-1275. http://dx.doi.org/10.1016/j.commatsci.2010.04.014.

15. Wahl, L.' Maas, S.; Waldman, D.; Zurbes, A.; Freres, P. 2011, Shear Stresses In Honeycomb Sandwich Plates: Analytical Solution, FEM, and Experimental Verification; University of Luxembourg

16. He, M.; Hu, W. 2008, A study on composite honeycomb sandwich panel structure. Materials and Design 29: 709-713. http://dx.doi.org/10.1016/j.matdes.2007.03.003.

17. Roy, R.; Park, SJ.; Kweon, JH.; Choi, JH. 2014, Characterization of Nomex honeycomb core constituent material mechanical properties. Composite Structures: $1-45$.

18. Cea, J.; Garreau, S.; Guillaume, Ph.; Masmoudi, M. 2000. The shape and topology optimization connection. Computer Methods in Applied Mechanics and Engineering, 188(4): 713-726. http://dx.doi.org/10.1016/S0045-7825(99)00357-6.

19. Amstutz, S.; Novotny, A.A. 2009. Topological optimization of structures subject to stress constraints. Proc. of $18^{\text {th }}$ Int. Conf. CMM 2009, Zielona Góra, Short Papers, 51-52.

20. Mrzygłód, M. 2009. Using layer expansion algorithm in topology optimization with stress constraints. Proc. of $18^{\text {th }}$ Int. Conf. CMM 2009, Zielona Góra, Short Papers, 319-320.

21. Bendsoe, M.; Sigmund, O. 2003. Topology Optimization. Theory, Methods and Applications. Sptinger Sciences\&Bussines Media, pp.370

22. Szczepanik, M.; Burczyński, T. 2012. Swarm optimization of stiffeners locations in 2-D structures. Bulletin of the Polish Academy of Sciences, Technical Sciences, Vol. 60, No. 2, 241-246.

23. Burczyński, T.; Poteralski, A.; Szczepanik, M. 2007. Topological evolutionary computing in the optimal design of 2D and 3D structures. Engineering Optimization, Vol. 39, No. 7, Taylor \& Francis, 811-830.
24. Poteralski, A. 2014. Optimization of Mechanical Structures Using Artificial Immune Algorithm, Beyond Databases, Architectures, and Structures (BDAS). Communications in Computer and Information Science, Vol. 424, Springer, 280-289.

25. Makowski, P.; Kuś, W. 2016. Optimization of bone scaffold structures using experimental and numerical data. Acta Mechanica, vol. 227, No. 1, 139-149, doi:10.1007/s00707-015-1421-4. http://dx.doi.org/10.1007/s00707-015-1421-4.

26. Nowak, M. 2006. Structural optimization system based on trabecular bone surface adaptation. Structural and Multidisciplinary Optimization, Vol. 32, No. 3, 241249.

http://dx.doi.org/10.1007/s00158-006-0027-9.

27. Nowak, M. 2009. Topology optimization with different material parameters using a biomimetic approach. Proc. of $18^{\text {th }}$ Int. Conf. CMM 2009, Zielona Góra, Short Papers, 337-338.

Małgorzata JOHN, Antoni JOHN, Wojciech SKARKA

THE INFLUENCE OF THE GEOMETRICAL

PARAMETERS ON THE MECHANICAL PROPERTIES OF THE HONEYCOMB STRUCTURE.

S u m m a r y

Based on the analogy with the biological tissue of bones, it was decided to examine more homogenous structure and also a heterogeneous structure too. In the paper new approach is proposed based on result obtained from topology optimization 2D and 3D structures like beam, girder and cantilever. Proposed model of structure is similar to spatial trusses with honeycomb-shape porous. Parameters varied not only uniformly throughout the volume of the sample, but also be modified depending on various factors. They underwent a change in cell dimensions, among other things, the thickness of the wall. The obtained results were compared with those obtained previously for homogeneous samples.

Keywords: honeycomb structures, numerical simulation, FEM, parametric model.

Received January 10, 2017

Accepted June 08, 2017 